\title{
İleri evre baş boyun kanserleri kanamalarında acil karotid arter ligasyonu
}

\author{
Urgent carotid artery ligation in advanced \\ head and neck cancer bleeding \\ Mehmet Sinan Başoğlu, Hale Aslan, Erdem Eren, Aslıhan Gürcan Bingölballı, \\ Murat Songu, Sedat Öztürkcan, Hüseyin Katılmış \\ İzmir Katip Çelebi Üniversitesi, Atatïrk Ĕ̆itim ve Araştırma Hastanesi, Kulak Burun Boğaz Hastalklarn Kliniği, İzmir
}

\begin{abstract}
Özet
Amaç: Baş boyun kanserli hastalarda tümör infiltrasyonuna bağlı kanama hayatı tehdit edecek boyutta olabilirse de, nadir rastlanan bir komplikasyondur ve acil girişim gerektirir. Bu çalışmada, kliniğimizde ileri evre baş boyun kanserli hastalarda görülen hayatı tehdit eden kanamalarda acil olarak yapılan karotid arter ligasyonu uygulamaları retrospektif olarak incelendi.

Yöntem: İleri evre baş boyun kanserli hastalarda gelişen hayatı tehdit eden kanama nedeniyle son sekiz yılda acil şartlarda karotid arter ligasyonu yapılan 12 hasta retrospektif olarak incelendi. Hastalar demografik özellikler, tanılar, tedavi yaklaşımları, ligasyon sonrası gelişen nörolojik komplikasyonlar ve mortalite açısından değerlendirildi.

Bulgular: Çalışmaya alınan 12 hastanın (2 kadın 10 erkek) yaş ortalaması 49.7 \pm 9.4 (alt-üst sınır 37-69) y1l idi. On hasta larenks veya hipofarenks karsinomu, bir hasta nazal malign melanom ve bir hasta da bukkal karsinom tanısı ile izlenmekte idi. Kanama, cerrahi ve radyoterapi sonrası nüks gelişen ( $\mathrm{n}=7$ ), inoperabl olarak değerlendirilip radyoterapi veya kemoradyoterapi uygulanan $(n=2)$, hiç tedavi almayan $(\mathrm{n}=2)$ ve cerrahi sonrası nüks olan $(\mathrm{n}=1)$ hastalarda görüldü. Tedavi amacı ile 10 hastaya (\%83.3) a. karotis kommunis, ikisine (\%16.7) a. karotis eksterna ligasyonu yapıldı ve tümünde kanama kontrolü sağlandı. Cerrahi sonrası nörolojik komplikasyon veya mortalite hiçbir hastada gözlenmedi.

Sonuç: Çalışmamızda ileri evre baş boyun kanserli hastalarda görülen hayatı tehdit eden kanamalarda acil olarak yapılan karotid arter ligasyonu uygulamalarının başarılı olduğu gözlendi. Sonuç olarak, tümör infiltrasyonuna bağlı kanamalarda karotid arter ligasyonunun güvenli ve etkili bir yöntem olduğu sonucuna varıldı.
\end{abstract}

Anahtar sözcükler: Baş boyun kanseri, karotid arter ligasyonu, hemoraji, komplikasyon.

\begin{abstract}
Objective: Although bleeding due to head and neck cancer infiltration is a rare complication, it may be life threatening and requires urgent intervention. The aim of this study was to investigate the efficiency of carotid artery ligation applications on bleeding patients with advanced head and neck cancer.

Methods: Urgent carotid artery ligation performed in the last 8 years for abundant bleeding in 12 patients with advanced stage head and neck cancer were analyzed retrospectively. The patients were evaluated in terms of demographic characteristics, diagnoses, treatment approaches, neurological complications and mortality.

Results: Mean age of 12 patients included in the study was $49.7 \pm 9.4$ (range 37-69), two of them were females (16.7\%) and 10 were males (83.3\%). Ten patients were diagnosed as carcinoma of larynx or hypopharynx, whereas one patient had nasal malign melanoma and one patient had buccal carsinoma. Abundant bleeding was observed in patients with recurrent disease after surgery and radiotherapy $(n=7)$, applied radiotherapy or chemoradiotherapy as considered inoperable $(\mathrm{n}=2)$, received no treatment $(\mathrm{n}=2)$ and patient with recurrence after surgery $(n=1)$. Common carotid artery ligation was performed in 10 patients and external carotid artery ligation was performed in two patients and hemostasis was achieved in all of them. No neurological complications or postoperative mortality were observed in any patients after ligation.

Conclusion: In our study, it was observed that application of urgent carotid artery ligation was successful in patients with bleeding due to advanced head and neck surgery. Therefore, it was concluded that carotid artery ligation was a safe and effective method for bleeding due to tumor infiltration.
\end{abstract}

Key words: Head and neck cancer, carotid artery ligation, hemorrhage, bleeding, complication.
İletişim / Correspondence: Dr. Mehmet Sinan Başoğlu. İzmir Katip Çelebi Üniversitesi, Atatürk Eğitim ve Araştırma Hastanesi, Kulak Burun Boğaz Hastalıkları Kliniği, Polat Cad., 353 Sok., No:53, Karabağlar, 35360 İzmir. e-posta: basoglusinan@gmail.com

Geliş tarihi / Received: Ekim / October 11, 2012; Kabul tarihi / Accepted: Ocak / January 7, 2013;

Online yayın tarihi / Published online: Mayıs / May 4, 2013

Çevrimiçi erişim / Online available at: www.jmedupdates.org doi:10.2399/jmu.2013001004 Karekod / QR code: 
Baş boyun kanserli hastalarda tümör infiltrasyonu, postoperatif radyoterapi tedavisine sekonder gelişen nekroz ve enfeksiyon nedenlerine bağlı olarak ortaya çıkan hayatı tehdit eden kanama, nadir görülen bir komplikasyondur ve prognostik bir önemi vardır. ${ }^{[1,2]}$ Tipik olarak ani gelişen hayatı tehdit eden kanamayla kendini gösterir ve en kısa sürede müdahaleyi gerektirir. Bu tür kanamalarda karotid arter ligasyonu en önemli tedavi seçeneklerinden biridir ancak yüksek mortalite riski ve hemipleji gelişme olasılı̆̆g gibi dezavantajları vardır. Literatürde elektif ligasyon sonras1 nörolojik sekel gelişme oranı \% 28 ve mortalite oranı ise \% 14-17 olarak bildirilmektedir. Buna karşın acil ligasyon uygulanan hastalarda \%25 oranında nörolojik komplikasyon ve \%64 oranında mortalite gözlenmektedir. ${ }^{[3]}$

Bu çalışmada, ileri evre baş boyun kanserli hastalarda görülen hayatı tehdit eden kanamalarda acil olarak yapılan karotid arter ligasyonu uygulamalarımız, tedavi başarısı, nörolojik komplikasyonlar ve mortalite açısından incelendi.

\section{Gereç ve Yöntem}

Kliniğimizde son sekiz yılda baş boyun kanserli hastalarda gelişen hayatı tehdit eden kanama nedeniyle acil şartlarda karotid arter ligasyonu yapilan 12 hasta retrospektif olarak incelendi. Hastalar demografik özellikler, tanılar, tedavi yaklaşımları, ligasyon sonrası gelişen nörolojik komplikasyonlar ve mortalite açısından değerlendirildi.

\section{Bulgular}

Çalışmaya alınan 12 hastanın (2 kadın 10 erkek) yaş ortalaması 49.7 \pm 9.4 (alt-üst sinır 37-69) yıl idi. On hasta larenks veya hipofarenks karsinomu, bir hasta nazal malign melanom ve bir hasta da bukkal karsinom tanısı ile izlen- mekte idi. Kanama, cerrahi ve radyoterapi sonrası nüks gelişen yedi hastada (\% 58.3), inoperabl olarak değerlendirilip radyoterapi veya kemoradyoterapi uygulanan iki hastada (\% 16.7), hiç tedavi almayan iki hastada (\% 16.7) ve cerrahi sonrası nüks olan bir hastada (\% 8.3) görüldü. Tedavi amac1 ile 10 hastaya (\%83.3) a. karotis kommunis, ikisine (\%16.7) a. karotis eksterna ligasyonu yapıldı ve tümünde kanama kontrolü sağlandı. Cerrahi sonrası nörolojik komplikasyon veya mortalite hiçbir hastada gözlenmedi. Hastaların özellikleri Tablo 1'de verilmiştir.

\section{Tartışma}

Baş-boyun bölgesinin malign tümörlerinde görülebilen acil kanama seyrek görülen bir ölüm nedenidir ve olguların \%5'inden azında gelişir. Tümör infiltrasyonu sonucu gelişen hayatı tehdit eden bu durum en ciddi ve korkutucu komplikasyondur. Kanama çoğunlukla karotid arteriyel sistemden kaynaklanır. Aktif cerrahi girişime kadar geçen sürede öncelikle yapılması gereken lokal basıdır ve mümkün olan en kısa sürede sedasyon, entübasyon ve cerrahi müdahale gerektirir. ${ }^{[4]}$ Ancak, bu kanamaların lokal olarak kontrolü, postoperatif anatomik değişiklikler, enfeksiyon ve radyonekroz gibi nedenlerle oldukça zor olmaktadır. Bu nedenle, bazı cerrahlar baş boyun bölgesinin malign tümörlerinde profilaktik olarak a. karotis eksternanın bağlanmasını savunmuşlar ve profilaktik ligasyon yapılan hastalarda hemorajiye sekonder mortalite oranının acil şartlarda yapılan girişime bağlı mortalite oranından belirgin derecede daha az olduğunu ileri sürmüşlerdir. ${ }^{[1]}$ Bu çalışmada, kliniğimizde son sekiz yılda hayatı tehdit eden kanama nedeniyle karotid arter ligasyonu yaptığımız ileri evre baş boyun kanserli hastalarımızı retrospektif olarak inceledik.

Tablo 1. Hastaların özellikleri.

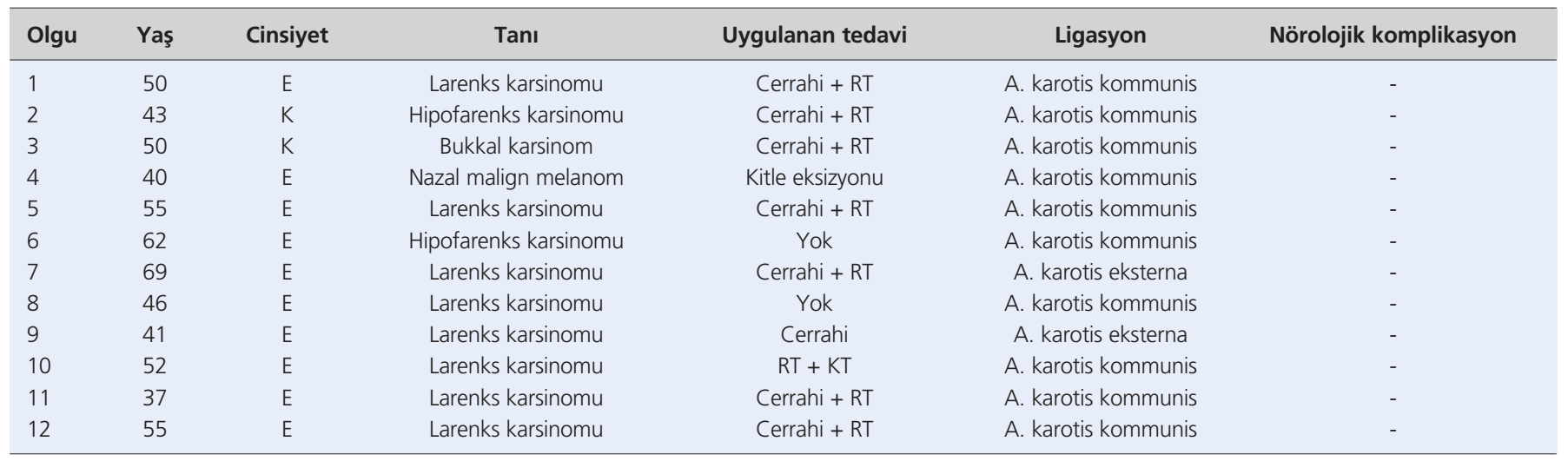

RT: Radyoterapi, KT: Kemoterapi, E: Erkek, K: Kadın. 
Baş boyun kanserli hastalarda gelişen hayatı tehdit eden kanamalarda karotid arter ligasyonu en önemli tedavi seçeneklerindendir. Diğger bir palyatif tedavi yöntemi ise girişimsel radyologların uyguladığı endovasküler tedavidir. Bu yöntemde femoral yolla girilerek kanayan damara anjio-embolizasyon yapılır. Ancak inme, körlük, nöbet ve tromboz gibi komplikasyonlara neden olabilmektedir. ${ }^{[5,6]}$ Ayrıca bu uygulama için deneyimli girişimsel radyologlara gereksinim vardır. Hastanemizde bu konuda deneyimli radyodiagnostik uzmanı bulunmaması nedeniyle endovasküler tedavi tercih edilmemiştir.

İleri evre baş boyun kanserli olgularda; özellikle anterolateral boyundaki yapıların tümöral infiltrasyona ve/veya radyoterapiye sekonder gelişen değişiklikler nedeniyle a. karotis eksternanın her zaman bulunup bağlanması mümkün olmayabilir. Bu amaçla, eksternal karotid artere posterior yaklaşım tercih edilerek sternokleidomastoid adalenin posteriorundan ulaşılması önerilmektedir. ${ }^{[7]} \mathrm{Kli}-$ niğimizde de a. karotis eksternanın bulunamadı $\breve{g} 1$ hastalarda a. karotis kommunis bağlanmıştır.

Karotid arteryel sistemin bağlanması sonucunda özellikle geç dönemde gelişen nörolojik komplikasyonlar açısından hastalar izlenmelidir. Literatürde kanama nedeniyle acil ligasyon yapılan olgularında \%64'lere varan mortalite ve \%25 oranında nörolojik komplikasyon bildirilmektedir. ${ }^{[8]}$ Elektif ligasyon sonrası ise nörolojik sekel oranı \%28 olarak bildirilmiş olup mortalite oranları \% 14-17 arasında değişmektedir. Bu komplikasyonlar genelde a. karotis kommunisin bağlanması sonucu meydana gelmektedir. Geç dönemde gelişen komplikasyonlardan başlıcaları geçici iskemik atak, stroke, serebrovasküler olay ve hipertansiyondur. ${ }^{[9]}$ Elektif vakalarda bildirilen bu nörolojik komplikasyonların ve mortalitenin bizim hastalarımızda görülmeme nedeni kronik süreç içinde kollateral gelişimi olabilir. Kollateral gelişimi sonrası, akut durumda yaşanan kanamaya bağlı metabolik değişiklikler ve nörolojik etkilenmeden en az hasarla çıkılması metabolizmanın uyumu ile açıklanabilir.

Calışmamızın bazı kısıtlılıkları bulunmaktadır. Bunların başında hasta sayısının az olması gelmektedir. Ancak bu tür olguların az görülmesi ya da hastaneye ulaşamadan kaybedilmesi gibi nedenlerle literatürdeki çalışmalarda da olgu sayı- sının sınırlı olduğu görülmüştür. Diğer bir kısıtlılık ise çalışmanın retrospektif olmasından dolayı girişim sonrası sağ kalım süreleri konusunda sağlıklı bilgi edinilememiş olmasıdır.

\section{Sonuç}

Sonuç olarak, bu çalışmada ileri evre baş boyun kanserli hastalarımızda acil koşullarda uyguladığımız karotid arter ligasyonu girişimi kanama kontrolünü sağlarken morbidite ya da mortaliteye neden olmamıştır. Bu nedenle, baş boyun kanserli hastalarda gelişen hayatı tehdit eden kanama durumunda gerekiyorsa acil şartlarda ligasyonun akılda tutulması gereken güvenli ve etkin bir girişim olacağ 1 kanısindayız.

Çıkar Çakışması / Conflict of Interest: Çıkar çakışması bulunmadığı belirtilmiştir.

\section{Kaynaklar}

1. Wurm J, Gode U, Fucak A. Ligature of the carotid arteries performed prophylactically or as an emergency procedure in patients with malignant tumours of the head and neck. HNO 2000;48:22-7.

2. Koopmann CF, Coulthard SW, Malone JM, et al. Complications of carotid artery replacement in head and neck neoplasms. Otolaryngol Head Neck Surg 1982;90:561-6.

3. Prokofev VE, Lebedev SN. Role of ligation of the external carotid artery in the treatment of malignant tumors of the tongue. Stomatologiia (Mosk) 2004;83:36-8.

4. Sesterhenn AM, Iwinska-Zelder J, Dalchow CV, et al. Acute haemorrhage in patients with advanced head and neck cancer: value of endovasculartherapy as palliative treatment option. J Laryngol Otol 2006;120:117-24.

5. Low YM, Goh YH. Intra-arterial embolisation in otolaryngology - a four-year review. Singapore Med J 2003;44:35-8.

6. Luo CB, Chang FC, Teng MM, et al. Endovascular treatment of the carotid artery rupture with massive hemorrhage. J Chin Med Assoc 2003;66:140-7.

7. Guerrissi JO, Yoel J. External carotid ligature: posterior approach (behind the sternocleidomastoid muscle). Int Surg 1977;62:601-2.

8. Roski RA, Spetzler RF, Nulsen FE. Late complications of carotid ligation in the treatment of intracranial aneurysms. Neurosurg 1981;54:583-7.

9. Winn HR, Richardson AE, Jane JA. Late morbidity and mortality of common carotid ligation for posterior communicating aneurysms. A comparison to conservative treatment. J Neurosurg 1977;47:727-36.

Bu açık erişim makalenin, ticari kullanım amacı ve içerik değişikliği dışında kalan çoğaltma, dağıtma vb. tüm kullanım hakları, bilinen standartlarda kaynak olarak gösterilmesi koşuluyla Creative Commons Attribution-NonCommercial-NoDerivs 3.0 Unported (CC BY-NC-ND3.0) Lisansı aracilığıyla (http://creativecommons.org/licenses/by-nc-nd/3.0/) bedelsiz kullanıma sunulmuştur.

Makalenin atıf künyesi: Başoğlu MS, Aslan H, Eren E, Gürcan Bingölballı A, Songu M, Öztürkcan S, Katılmış H. İleri evre baş boyun kanserleri kanamalarında acil karotid arter ligasyonu. J Med Updates 2013;3(1):31-33. 